\title{
Article
}

\section{Geometrical characteristics of externally venting flames: Assessment of fire engineering design correlations using medium-scale compartment-façade fire tests}

\author{
Asimakopoulou, Eleni, Kolaitis, Dionysios and Founti, Maria \\ Available at http://clok.uclan.ac.uk/31936/ \\ Asimakopoulou, Eleni ORCID: 0000-0001-5644-1372, Kolaitis, Dionysios and \\ Founti, Maria (2016) Geometrical characteristics of externally venting flames: \\ Assessment of fire engineering design correlations using medium-scale \\ compartment-façade fire tests. Journal of Loss Prevention in the Process \\ Industries, 44 . pp. 780-790. ISSN 0950-4230
}

It is advisable to refer to the publisher's version if you intend to cite from the work. http://dx.doi.org/10.1016/j.jp.2016.09.006

For more information about UCLan's research in this area go to

http://www.uclan.ac.uk/researchgroups/ and search for < name of research Group>.

For information about Research generally at UCLan please go to http://www.uclan.ac.uk/research/

All outputs in CLoK are protected by Intellectual Property Rights law, including Copyright law. Copyright, IPR and Moral Rights for the works on this site are retained by the individual authors and/or other copyright owners. Terms and conditions for use of this material are defined in the policies page. 


\title{
Evaluation of fire engineering design correlations for externally venting flames using medium-scale compartment-façade fire tests
}

\section{(New title is: Geometrical characteristics of externally venting flames: Assessment of fire engineering design correlations using medium-scale compartment-façade fire tests)}

\author{
Eleni K. Asimakopoulou ${ }^{1}$, Dionysios I. Kolaitis ${ }^{1, *}$ and Maria A. Founti ${ }^{1}$ \\ ${ }^{1}$ Laboratory of Heterogeneous Mixtures and Combustion Systems, Thermal Engineering Section, \\ School of Mechanical Engineering, National Technical University of Athens, \\ 9, Heroon Polytechniou St., Polytechnioupoli Zografou, Athens 15780, GREECE.
}




\begin{abstract}
In a fully developed under-ventilated compartment fire, flames may spill out of external openings (e.g. windows); Externally Venting Flames (EVF) pose a significant risk of fire spreading to adjacent floors or buildings. The main aim of this work is to comparatively assess a range of fire engineering design correlations used to describe the external dimensions of the EVF envelope. The predictive accuracy of each correlation is evaluated through comparison with experimental data obtained in a medium-scale compartment-façade fire facility, using typical fire loads suggested in the Eurocode. A series of fire tests is performed, employing a 1/4 scale model of the ISO 9705 room, equipped with an additional extended façade. An "expendable" fuel source (n-hexane) is utilized to effectively simulate realistic building fire conditions. An extensive sensor network is used to monitor the dynamic behaviour of a broad range of important EVF physical parameters and a dedicated image processing tool is developed to allow estimation of the EVF envelope main dimensions (e.g. height, width, projection). Digital camera imaging is used to determine the main geometrical characteristics of the EVF envelope. Comparison of fire engineering design correlation predictions with experimental data reveals that correlations for the estimation of EVF height err on the safe side in under-ventilated fire conditions; decreasing the fire load results in under-prediction of EVF height and projection. It is shown that EVF projection and width strongly depend on both excess heat release rate and height. In addition, the necessity to derive appropriate criteria for the identification of the EVF projection is demonstrated. The obtained extensive set of experimental data, covering three different fire load levels, can be also used to validate numerical simulation tools or evaluate the accuracy of other available fire design correlations.
\end{abstract}

\title{
Keywords
}

Externally Venting Flames (EVF), fire engineering design, façade fire, flame dimensions, fire test, measurements 


\section{Introduction}

In a fully developed under-ventilated compartment fire, flames may spill out of external openings (e.g. windows), should the glazing fail. Externally Venting Flames (EVF) pose a significant risk of fire spreading to adjacent floors or buildings; this risk is constantly increasing due to the rising use of combustible insulation materials in building façades [1]. However, the majority of current fire safety codes are lacking accurate methodologies to evaluate the risks associated with EVF, especially in an ever-changing construction market where new façade design requirements and construction materials challenge the established fire safety solutions.

In order to effectively act towards EVF prevention and mitigation of external fire spread, it is essential to investigate the fundamental physical phenomena associated with EVF. Research on EVF, focused on identifying the main physical parameters governing internal fire dynamics and consequent EVF, commenced in the early 1960's by Yokoi [2] and was further expanded by others [3-5]. Some findings of the respective research regarding EVF description and its impact on façades have been gradually incorporated in fire safety codes and design guidelines. The Eurocode design guidelines [6], currently implemented in the E.U., provide general principles and rules regarding thermal and mechanical actions on structures exposed to fire; fire actions for designing load-bearing structures are prescribed in EN 1991-1-2 (Eurocode 1) [6]. However, fire spreading due to combustible façade materials is not addressed at all in the Eurocode guidelines and there is only a coincidental reference to risks associated with EVF (i.e. protection of steel and timber building elements).

This work is motivated by an increasing number of recent reports [7-11] suggesting that existing engineering design methodologies cannot describe with sufficient accuracy the characteristics of EVF under realistic fire load conditions. The main scope of this work is to comparatively assess fire engineering design correlations used to describe the external dimensions of the EVF envelope $[5,6,12]$. Aiming to investigate in detail the fundamental nature of EVF and motivated by the lack of fully accessible experimental data relevant to compartment-façade fire tests in the open literature, the authors have conducted their own medium-scale fire tests. In this work, both thermal and geometric characteristics of EVF are reported in detail and an evaluation of the EVF plume dimensions semi-empirical correlations against medium-scale, as presented in the current work, and large-scale experimental data, as presented in authors' previous work [11], has been conducted. The predictive accuracy of each correlation is evaluated through comparison with experimental data obtained in a medium scale compartment-façade fire arrangement. The obtained extensive set of experimental data, covering a range of fire load levels, can be further used to validate Computational Fluid Dynamics (CFD) tools or evaluate the accuracy of other available fire design correlations. 


\section{Fire Engineering Design Correlations Related to EVF}

There are several fire engineering design correlations available [2-4, 7, 8, 11], aiming to describe the main characteristics of EVF that may affect the fire safety design aspects of a building, such as the EVF's height, projection, temperature and heat flux to the façade. These semi-empirical correlations have been derived using simplified theoretical analyses in conjunction with experimental data $[2,13]$. Although EVF exhibit significantly different characteristics depending on the number and position of openings in the fire compartment, in this work only fire compartments with a single opening are investigated.

Estimation of EVF dimensions and main thermal characteristics is commonly based on using the conservation laws of mass, momentum and energy for upward gas flows [2, 10, 14]. During the initial stages of fire development, combustion is limited at the interior of the fire compartment. Incoming air enters the compartment through the lower part of the opening, whereas hot gaseous combustion products exit through the upper part of the opening. Depending on the size of the compartment and the fire load, it is possible to have a fire plume that cannot be contained within the compartment; in this case flames are ejected through the opening, due to the expansion of the buoyant turbulent flame at the exterior of the compartment [7, 8, 11]. The geometrical characteristics of the EVF envelope are known $[6,14]$ to be affected by fire heat release rate, average height of the opening(s), total area of the opening(s) and external wind speed. Even though the geometrical boundaries of the EVF envelope are dynamically changing with time, fire engineering correlations commonly assume a steady-state EVF shape, prescribed via EVF height $\left(L_{L}\right)$, projection $\left(L_{H}\right)$ and width $\left(w_{f}\right)$ (Fig. 1). EVF is commonly considered to project from the upper part of the opening, initially at an angle but, due to thermal buoyancy effects, the fire plume eventually advances vertically, parallel to the façade wall (Fig. 1).

A selection of semi-empirical fire engineering design correlations, used to estimate the EVF height $\left(L_{L}\right)$ and projection $\left(L_{H}\right)$, is presented in Table 1 [2, 5, 6, 11-13, 15-17]. The majority of these correlations has been derived using experimental data from open air pool fires (free fire plume), but they can also be safely used for the determination of the EVF shape, assuming that the fuel source corresponds to the upper half of the opening $[11,14]$. In this case, the flow outside the enclosure is assumed to originate from a "fictitious" rectangular burner located vertically on the upper half of the opening; only the convective fraction of the fire at the opening is considered. All correlations, with the sole exception of correlation $\mathrm{H} 3$, can be used for both under-ventilated (UV) and over-ventilated (OV) fire conditions.

Correlations H1 and P1, suggested in EN 1991-1-2 [6], are based on the correlations proposed by Law [13]. Assuming an axisymmetric buoyant plume, correlation H2 [12] uses the "effective" area of the fire source $\left(D_{v}\right)$ to estimate the mean EVF height. The latter quantity represents the area of the opening through which the EVF is ejected and it is commonly assumed to correspond to the upper half of the opening area (Equation 1) [3, 5]. 


$$
\begin{gathered}
D_{v}=A_{v} / 2 \\
l=\left(A \sqrt{h_{e q}}\right)^{2 / 5}
\end{gathered}
$$

A modified model for the estimation of EVF height, expressed via correlation $\mathrm{H} 3$, was recently proposed [5]; the characteristic length scale $l$ is calculated using Equation (2). The excess heat release rate $\left(\dot{Q}_{e x}\right)$, appearing in correlation $\mathrm{H} 3$, corresponds to the fraction of the total heat release rate that is owed to combustion that takes place exclusively outside of the fire compartment (EVF). For under-ventilated conditions [5], $\dot{Q}_{e x}$ can be estimated as the difference between the total heat release rate $\left(\dot{Q}_{t o t}\right)$ and the average heat release rate at the interior of the fire compartment $\left(\dot{Q}_{i n, \max }\right.$ ) (Equation 3). The latter quantities can be estimated using Equations (4) and (5).

$$
\begin{gathered}
\dot{Q}_{e x}=\dot{Q}_{t o t}-\dot{Q}_{i n, \max } \\
\dot{Q}_{t o t}=\dot{m}_{f} H_{u} \\
\dot{Q}_{i n, \max }=1500 A_{v} \sqrt{h_{e q}}
\end{gathered}
$$

Correlations P2 [2], P3 [16] and P4 [17], used to estimate the EVF projection, are based on flow analysis methodologies assuming non-radiative heat sources located at the upper half of the opening. Although some $[2,12,16,17]$ of the correlations are derived from open air pool fire experimental data, they can be also used for the determination of EVF average dimensions by assuming the upper half of the opening as the fuel source (Equation 1) [14]. In such a case, only the convective fraction of the heat release rate at the opening is taken into account [19].

The EVF width $\left(w_{f}\right)$ is commonly assumed to be equal to the opening width $\left(w_{t}\right)[6,13]$; only scarce reports in the literature [18] indicate its dependence on EVF height and aspect ratio of the opening $\left(w_{t} / h_{e q}\right)$. It has been observed that when the fire load burns unevenly, it may result in asymmetric EVF projection and width [13]; such behaviour is not taken into account in any of the correlations currently available. In all cases, the external dimensions of an EVF are assumed 
constant in time (steady-state conditions) enabling estimation of the geometrical properties using simple trigonometry rules $[6,10,13]$.

\section{Experimental Setup}

\subsection{Medium-Scale Compartment-Façade Fire Facility}

A series of fire tests were conducted in a medium-scale compartment-façade fire facility. The compartment was a $1 / 4$ scale model of an ISO 9705 room [20]. The internal compartment dimensions were $0.60 \mathrm{~m} \times 0.90 \mathrm{~m} \times 0.60 \mathrm{~m}$; the external facade wall measured $0.658 \mathrm{~m} \times 1.8 \mathrm{~m}$. A double layer of $12.5 \mathrm{~mm}$ thick fire-resistant gypsum plasterboards was used as the internal (compartment) and external (façade) lining material. The fire compartment opening, corresponding to an open door, located at the middle of the northern wall, measured $0.20 \mathrm{~m} \times 0.50$ $\mathrm{m}$. The effective area of the fire source $\left(D_{v}\right)$ was equal to $0.05 \mathrm{~m}^{2}$. A schematic of the experimental facility, illustrating the locations of the employed measuring devices, is given in Figure 2.

\subsection{Parametric Study}

Gaseous burners are commonly used in relevant fire compartment experiments [4, 5, 18], to provide a constant (steady-state conditions) fire source. However, aiming to achieve more "realistic" fire conditions, relevant to actual building fires, an "expendable" (transient conditions) liquid fuel source was used. A stainless steel rectangular pan, measuring $0.25 \mathrm{~m} \times 0.25 \mathrm{~m} \times 0.10$ $\mathrm{m}$, was installed at the geometrical centre of the compartment's floor; n-hexane was used as the liquid fuel of choice. The mass of the fuel was continuously monitored via a load cell, installed under the fuel pan. The fuel pan size was selected in order to achieve under-ventilated fire conditions, thus forcing the flames to eject through the opening.

A series of fire tests were conducted by modifying the total fuel load. The overall design of the fire tests was based on the hypothesis that a "full-scale" physical phenomenon can be simulated using a "reduced scale" model. Selection of the fire load for the "benchmark" case, test case D4.70L, was based on the typical design fire load density suggested in EN 1991-1-2 [6] for office premises $\left(511 \mathrm{MJ} / \mathrm{m}^{2}\right)$. This "full-scale" fire load density value was scaled by employing the Buckingham $\pi$ theorem, resulting in a "reduced scale" design fire load density of $250 \mathrm{MJ} / \mathrm{m}^{2}$ [11]. Test case D-4.70L was the main case used for the assessment of the fire engineering design correlations. Two additional test cases (D-2.35L, D-1.00L) were investigated in order to further explore the effects of fire load and ventilation conditions in the EVF characteristics.

As it has been demonstrated in previous studies [7, 8, 11], the fuel mass loss rate and the compartment geometry have a significant impact on fire development and the prevailing 
ventilation conditions in a fire compartment. The ventilation conditions established in a fire compartment can be determined by estimating the Global Equivalence Ratio (GER); GER values higher than 1.0 signify under-ventilated conditions (ventilation-controlled fire), whereas GER values less than 1.0 correspond to an over-ventilated case (fuel-controlled fire). For a single compartment fire, the average GER value can be determined using Equation (6), by employing the total heat release rate of the fire and the mass flow rate of air entrained into the compartment [21]. The latter quantity can be estimated using Equation (7). The fire ventilation regime for each fire test performed in this work was determined by employing Equations (4), (6) and (7). Test cases D-2.35L and D-4.70L corresponded to mainly under-ventilated fire conditions, whereas in test case D-1.00L, a slightly over-ventilated fire was developed, due to the low fire load used [11].

$$
\begin{gathered}
G E R=\frac{\dot{Q}_{t o t}}{\dot{m}_{a}} \cdot \frac{1}{3030} \\
\dot{m}_{a}=0.5 A_{v} \sqrt{h_{e q}}
\end{gathered}
$$

A summary of the main operational parameters, i.e. fuel volume $\left(V_{f}\right)$ and mass $\left(m_{f}\right)$, ambient temperature $\left(T_{\infty}\right)$ and relative humidity $\left(R H_{\infty}\right)$, total fire duration $\left(t_{d u r}\right)$, average Global Equivalence Ratio $(G E R)$, fire load density $\left(q_{f}\right)$ total heat release rate $\left(\dot{Q}_{t o t}\right)$, maximum heat release rate at the interior of the fire compartment $\left(\dot{Q}_{i n, \max }\right)$ and excess heat release rate at the exterior of the compartment $\left(\dot{Q}_{e x}\right)$ [5], for the 3 test cases examined, is shown in Table 2. The total heat release rate is estimated using the fuel consumption rate measurements and the lower heating value of $\mathrm{n}$ hexane, assuming an (ideal) 100\% combustion efficiency (Equation 4). The maximum heat release rate at the interior of the compartment is calculated using Equation (5) [11].

\subsection{Sensor Network}

The overall thermal behaviour of the compartment-façade configuration was investigated by measuring temperatures and heat fluxes at various locations (Figure 2). Ten K-type $1.5 \mathrm{~mm}$ diameter thermocouples, distributed in two thermocouple trees located at the front (location CF) and rear (location $\mathrm{CB}$ ) corner of the compartment were used to monitor the temperature profiles developing at the interior of the fire compartment. The recorded thermocouple data, obtained at the interior of the compartment, were corrected for radiation using a "post-processing" methodology [11]. In addition, four thermocouples were vertically distributed at the centreline of the opening, aiming to record the thermal characteristics of the fire-induced opening flow. Special 
emphasis was given to the characterization of the temperature environment adjacent to the façade wall along the height of the fire plume, both at the centreline (location T1C) and at an off-axis position, $164.5 \mathrm{~mm}$ from the centreline (location T1M). Towards this end, $14 \mathrm{~K}$-type thermocouples were placed at various locations across the façade wall. In addition, $39 \mathrm{~K}$-type thermocouples were distributed at the exterior of the compartment-façade facility. The latter thermocouples were distributed among two thermocouple trees, fixed in two characteristic positions across the EVF width, one at the centre-line of the opening (location T1C) and the other corresponding to $1 / 4$ of the total façade width (location T1M). The thermocouples were located at nine height levels above the floor $(200,400,600,710,800,850,1000,1200$ and $1500 \mathrm{~mm})$; two thermocouples were used at each height level, corresponding to a distance of $123 \mathrm{~mm}$ and $246 \mathrm{~mm}$ from the façade wall. At three characteristic height levels (400, 800 and $1200 \mathrm{~mm}$ ), thermocouples were installed at nine locations (at a distance of 10, 60, 110, 160, 210, 260, 310, 410 and $510 \mathrm{~mm}$ from the façade surface).

The estimation of experimental errors has been presented in detail in a previous work [11]; a summary of the estimated measurement uncertainty for the thermocouple measurements is presented in Table 3. A water-cooled, $25 \mathrm{~mm}$ diameter, Schmidt-Boelter heat flux sensor was placed at the centreline of the façade surface facing the EVF, $110 \mathrm{~mm}$ above the opening lintel. All thermocouples and heat flux measurements were recorded using a Universal Data Logging Interface designed in LabView software; the sampling frequency was $1.0 \mathrm{~Hz}$.

Two digital video cameras were positioned at two locations, directly opposite and at a right angle to the opening, to record the developing EVF envelope at 30 frames per second. Time series of video frames were obtained and processed using an in-house developed MATLAB code, aiming to determine the geometric characteristics of the EVF envelope. Each image frame was cropped, aligned and assigned proper world coordinates. A modified version of the methodologies proposed by Vipin and Celik et al. [22, 23] was used. Each frame was converted into a binary image using a set of rules, employing appropriate threshold limits for Red, Green and Blue colour levels and luminosity, based on the prevailing lighting conditions in each test case. The threshold limits were acquired through an extended statistical analysis of the various flame regions in each stage of the flame cycle. The EVF envelope dimensions were determined by calculating the average flame probability (intermittency). Early research [16] has indicated that the fire plume above a fuel source can be divided into three main regions, characterised by the probability of flame presence. Using flame intermittency criteria, these three distinct regions, namely the "continuous flame", the "intermittent flame" and the "far-field plume", can be also identified in EVF [5, 21]. In this context, the flame heights corresponding to the "continuous flame" ( $L_{f_{-} 0.95}, 95 \%$ intermittency),

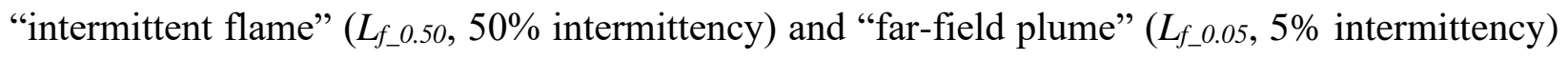
regions were obtained; beyond these regions the flame cannot be seen and only hot combustion products are present. The mean EVF height $\left(L_{f, m}\right)$ can be estimated using either the $50 \%$ flame intermittency limit $\left(L_{f_{-} 0.50}\right)$, or, alternatively, by averaging the estimated flame height at the "continuous flame" $\left(L_{f_{-} .05}\right)$ and "far-field plume" $\left(L_{f_{-} 0.95}\right)$ regions [24, 25]; values obtained using 
both methodologies are in very good agreement. A thermal camera was positioned $6.0 \mathrm{~m}$ away from the façade to record additional information regarding the thermal response of the façade surface.

\section{Results and Discussion}

\subsection{Fuel Consumption Rate}

The combustion rate of pool fires in compartments is influenced by a variety of parameters, such as ventilation, radiation from the surrounding walls and thermal characteristics of the exposed rim above the fuel $[3,21]$. The effects of these parameters are evident in Figure 3, where measurements of the instantaneous fuel mass loss rate for all the examined test cases are depicted. It is evident that higher initial fuel mass results in enhanced fuel combustion rates. In addition, as time advances, the gradual lowering of the liquid fuel level results in a slight increase of the instantaneous fuel combustion rate.

\subsection{Compartment Gas Temperatures}

The gas temperature evolution inside the compartment exhibits similar characteristics for each test case; the three main stages of "fire growth", "fully-developed fire" (quasi steady-state conditions) and "fire decay", typically encountered in compartment fires, can be easily identified (Figure 4). Figure 4 depicts the temporal variation of the upper gas layer temperature at the interior of the fire compartment. The reported temperatures are the average values of thermocouple measurements obtained at the front (position CF) and rear (position CB) of the fire compartment, at several heights lying inside the upper gas layer (300, 400 and $500 \mathrm{~mm}$ from the compartment floor). Time-averaged temperature profiles along the height of the compartment are presented in Figure 5. As expected, higher fire loads result in higher mean gas temperatures. The vertical distribution of the time-averaged gas temperature at the front of the compartment, near the opening (location CF), is notably higher in Test case D-4.70L, indicating that combustion still occurs further away from the fuel pan, resulting in a larger EVF ejecting from the opening (c.f. Figure 7).

\subsection{EVF Gas Temperatures}

Figure 6 depicts the vertical distribution of time-averaged values for the mean EVF gas temperature, at a distance of $123 \mathrm{~mm}$ (location T1C) and $246 \mathrm{~mm}$ (location T2C) away from the façade. Values are time-averaged for the entire duration of each fire test. All measurement locations correspond to the EVF envelope, covering both the "continuous flame" and the "intermittent flame" regions. Temperatures at the "continuous flame" region remain practically 
constant; a slight temperature decrease is observed throughout and above the "intermittent flame" zone. Temperature histories at a height level of $850 \mathrm{~mm}$ and $1500 \mathrm{~mm}$, at a distance of $123 \mathrm{~mm}$ (locations T1C and T1M) and $246 \mathrm{~mm}$ (locations T2C and T2M) from the façade, are presented in Figure 7. In Test case D-4.70L, significantly higher EVF temperatures are observed, compared to Test cases D-1.00L and D-2.35L.

\subsection{EVF Envelope Dimensions}

The time-averaged spatial distribution of the flame envelope probability, expressed via the flame intermittency, is illustrated in Figure 8 (image artifacts are owed to the presence of the thermocouple trees). In general, the overall EVF volume increases with increasing heat release rate. The EVF shape in low fire load and over-ventilated fire conditions (Test case D-1.00L), is significantly limited in comparison to higher fire load and under-ventilated fire conditions (Test cases D-2.35L and D-4.70L). In general, the EVF envelope tends to assume an elliptical shape, which is compatible to the EVF shapes proposed in widely used engineering design methodologies $[2,10]$.

Flame ejection through the opening occurs due to ignition of the excess (unburnt) fuel and expansion of the buoyant turbulent flame at the exterior of the compartment. Whether an EVF would develop mainly depends on the fuel concentration and the temperature of the hot unburnt gases exiting the fire compartment. A summary of estimated values for the EVF height at the continuous $\left(L_{f_{-} 0.95}\right)$, intermittent $\left(L_{f_{-} 0.50}\right)$ and far field $\left(L_{f_{-} 0.05}\right)$ regions, mean EVF height $\left(L_{f, m}\right)$, mean width $\left(w_{f}\right)$ and projection $\left(L_{H}\right)$ is presented in Table 4. The mean EVF height $\left(L_{f, m}\right)$ corresponds to the mean value of $L_{f_{-} 0.05}$ and $L_{f_{-}} 0.95$. The EVF probability $(P)$ corresponds to the fraction of the total fire duration that EVF is observed to emerge at the exterior of the fire compartment; $P$ is strongly affected by the overall heat release rate, an observation that agrees with similar remarks found in the literature [26].

Figure 9 illustrates the methodology followed to estimate the mean flame height. The variation of time-averaged flame intermittency with height, at the centreline of the flame, is depicted; flame intermittency decreases with height from higher values (close to 1) to smaller values (in the intermittent flame region) until zero values are reached. The mean flame height $\left(L_{f, m}\right)$ is assumed to be equal to the largest height value where $50 \%$ flame intermittency $\left(L_{f_{-} 0.50}\right)$ is observed (marked with an asterisk in Figure 9). In Figure 9, EVF height predictions, using the semi-empirical correlations H1, H2 and H3 (c.f. Table 1) are also depicted for test cases D-2.35L and D-4.70L (conditions in test case $\mathrm{D}-1.00 \mathrm{~L}$ are outside the applicability range of these correlations).

The temporal evolution of the instantaneous EVF height for test case D-4.70L, expressed via the $L_{f_{-} 0.50}$ at the centreline, is illustrated in Figure 10; these values were estimated using the methodology presented in Figure 9 using each time frame captured in the cameras. A typical behaviour for an EVF developing in an under-ventilated compartment fire can be observed [27], 
which is characterized by 3 distinct phases that appear in succession. Initially, combustion is constrained in the interior of the fire compartment ("internal flaming"). Gradually, the flame front moves away from the fuel pan, expanding radially and horizontally towards the opening. In that point, external flame jets and quick flashes appear at the exterior of the fire compartment, signifying the beginning of the "intermittent flame ejection" stage. As time passes, "consistent external flaming" is observed due to the sustained external combustion of unburnt fuel, during the quasi-steady phase of fully-developed fire. Throughout the latter phase, EVF consistently covers the region above the opening resulting in higher values of EVF height.

The EVF projection $\left(L_{H}\right)$ was estimated using the time-averaged values of the flame intermittency at a height of $0.9 \mathrm{~m}$ above the ground level. Unlike to the calculation methodology used to evaluate $L_{f_{-}} 0.50$, estimation of the mean value of $L_{H}$ is not a straightforward procedure, since the flame intermittency is not monotonically decreasing. In this case, $L_{H}$ was assumed to be equal to the largest distance from the façade where a 50\% flame intermittency is observed (marked with an asterisk). Figure 11 depicts schematically the variation of flame intermittency as a function of the distance from the façade; estimated values for the EVF projection, using the semi-empirical correlations P1-P4 presented in Table 1, are also depicted. The values of $L_{f_{-}} 0.50$, estimated using the methodology presented above, were used to determine the mean flame height $\left(L_{L}\right)$ values required in correlations $\mathrm{P} 2-\mathrm{P} 4$.

In Figure 12, the vertical distribution of the time-averaged EVF width $\left(w_{f}\right)$ and projection $\left(L_{H}\right)$ during the continuous external flaming period, estimated using the presented methodology, is presented. The EVF width is found to generally increase with increasing height, until it reaches its maximum value, where it starts to decrease again. This remark is not in agreement with the common assumption used in fire design guidelines [6], where $w_{f}$ is assumed to remain constant and is considered to be equal to $w_{t}$ [28]. In Test cases D-2.35 and D-4.70, characterised by underventilated fire conditions, longer EVF projection values are generally observed.

Summary of EVF dimensions relative error estimation using semi-empirical correlations of experimental data from medium-scale, as conducted in the frame of the current work, and largescale fire tests, as found in literature [11], are tabulated in Table 5. For medium-scale configurations, good levels of quantitative agreement are observed when EVF height is estimated; fire engineering design correlations, $\mathrm{H} 1, \mathrm{H} 2$ and $\mathrm{H} 3$, are found to err on the safe side when underventilated fire conditions prevail. In all medium,-scale test cases, only estimations of the EVF projection using correlation $\mathrm{P} 1$ errs on the safe side, whereas this is not the case for the rest of the correlations. Generally, only correlations used in EN 1991-1-2 [6] accurately predict mediumscale experimental data. For large scale-configurations, namely test cases 2, 8, 28 and 29, correlations for the estimation of EVF height mostly under-predict experimental data. This is also the case for EVF projection, where all correlation, except P1, tend to significantly underestimate the experimentally determined values. 


\section{Conclusions}

The objective of this study was the evaluation of available fire engineering design correlations aiming to estimate the geometric characteristics of EVF, using a series of medium-scale compartment-façade fire tests. Digital camera recordings were used for the determination of the dynamically changing EVF envelope. Predictions using the semi-empirical correlations for the estimation of the EVF height $\left(L_{L}\right)$, projection $\left(L_{H}\right)$ and width $\left(w_{f}\right)$ were compared against the obtained medium scale and found in literature large scale experimental data.

Correlations for the estimation of $L_{L}$ were found to lie on the safe side in under-ventilated fire conditions in medium scale experiments under No Forced Draught conditions, though their applicability is limited, whereas for large scale configurations they generally under predict experimental data; increasing the heat release rate results in over-prediction for both $L_{L}$ and $L_{H}$, in medium scale conditions.

The $w_{f}$ is commonly assumed to be equal to the opening width; only scarce reports in the literature indicate its dependence on EVF height and aspect ratio of the opening. Values of flame projection $\left(L_{H}\right)$ and flame width $\left(w_{f}\right)$ were found to strongly depend on both excess heat release rate from the compartment fire and height from the ground. The necessity to derive appropriate criteria for the identification of $L_{H}$ was demonstrated. In all the investigated correlations, the external dimensions of the EVF are assumed constant in time (steady-state conditions), enabling the estimation of the relevant geometrical properties using simple trigonometry rules, nevertheless, the current work's experimental observations strongly indicate the need to derive time dependent correlations.

The obtained extensive set of experimental data, pertaining to both the interior and exterior of the fire compartment, can be used to validate CFD models or evaluate the accuracy of other available fire design correlations.

\section{Acknowledgements}

This study has been financially supported by the "Fire-FACTS" project in the frame of the ARISTEIA action (operational programme "Education and Lifelong Learning") that is co-financed by Greece and the E.U. and by the E.C. in the frame of two FP7 projects, "MeeFS: Multifunctional Energy Efficient Façade System for Building Retrofitting" (EeB.NMP.2011-3, Grant No. 285411) and "ELISSA: Energy Efficient Lightweight-Sustainable-Safe-Steel Construction" (EeB.NMP.2013-1, Grant No. 609086). The assistance of Dipl. Eng. Konstantinos Chotzoglou in the development, installation and testing phases of this work is gratefully acknowledged.

\section{References}

[1] White, N., \& Delichatsios, M. (2014). Fire Hazards of exterior wall assemblies containing combustible components. Final Report, Fire Protection Research Foundation. 
[2] Yokoi, S. (1960). Study on the prevention of fire spread caused by hot upward current. Building Research Institute, Report No. 34, Tokyo, Japan.

[3] Asimakopoulou, E., Kolaitis, D., \& Founti, M. (2016) Characteristics of Externally Venting Flames and their effect on the façade: A detailed experimental study. Fire Technology (doi: 10.1007/s10694-016-0575-5).

[4] Oleszkiewicz, I. (1989). Heat transfer from a window fire plume to a building façade. Reprinted from "Collected papers in heat transfer", HTD-Vol. 123, Editors: Marner, W. J., Chen, T. C., Faghri, M., Peterson, G. P., Kuehn, T. H., Pate, M. B., Mahajan, R. L., \& Lavine, A. S., Book No. H00526.

[5] Tang, F., Hu, L. H., Delichatsios, M. A., Lu, K. H., \& Zhu, W. (2012). Experimental study on flame height and temperature profile of buoyant window spill plume from an under-ventilated compartment fire. International Journal of Heat and Mass Transfer, 55, 93-101.

[6] Eurocode 1, EN 1991-1-2 (2002). Actions on structures, Part 1-2 - General Actions - Actions on Structures Exposed to Fire. Brussels, Belgium.

[7] Klopovic, S., \& Turan, O. F. (2001). A comprehensive study of externally venting flames, Part I: Experimental plume characteristics for through-draft and no through-draft ventilation conditions and repeatability. Fire Safety Journal, 36, 99-133.

[8] Klopovic, S., \& Turan, O. F. (2001). A comprehensive study of externally venting flames, Part II: Plume envelope and center-line temperature comparisons, secondary fires, wind effects and smoke management system. Fire Safety Journal, 36, 135-172.

[9] Empis, C. A. (2010). Analysis of the compartment fire parameters influencing the heat flux incident on the structural façade. Ph.D. Thesis, University of Edinburgh, U.K.

[10] Himoto, K., Tsuchihashi, T., Tanaka, Y., \& Tanaka, T. (2009). Modeling thermal behaviors of window flames ejected from a fire compartment. Fire Safety Journal, 44, 230-240.

[11] Asimakopoulou, E., Kolaitis, D., \& Founti, M. (2016) Assessment of fire engineering design correlations used to describe the geometry and thermal characteristics of Externally Venting Flames. Fire Technology (doi: 10.1007/s10694-016-0594-2).

[12] Heskestad, G. (1983). Virtual origins of fire plumes. Fire Safety Journal, 5, 109-114.

[13]Law, M. (1978). Fire safety of external building elements - The design approach. AISC Engineering Journal, Second Quarter.

[14] Beyler, C. L. (1986). Fire plumes and ceiling jets. Fire Safety Journal, 11, 53-75.

[15] Hasemi, Y., \& Tokunaga, T. (1984). Flame geometry effects in the buoyant plumes from turbulent diffusion flames. Fire Safety Science and Technology, 4, 15-26.

[16] McCaffrey, B. J. (1983). Momentum implications for buoyant diffusion flames. Combustion and Flame, 52, 149-156.

[17] Beuther, P. D., \& George, W. K. (1982). Measurement of the turbulent energy and temperature balances in an axisymmetric buoyant plume in a stably stratified environment. Proceedings of the $7^{\text {th }}$ International Heat Transfer Conference, 163-178, Munich, Hemisphere Press, NY. 
[18] Delichatsios, M., Lee, Y., \& Tofilo, P. (2009). A new correlation for gas temperature inside a burning enclosure. Fire Safety Journal, 44, 1003-1009.

[19] Korhonen, T., \& Hietaniemi, J. (2005). Fire safety of wooden façades in residential suburb multi-storey buildings. VTT Working Papers 32, Finland.

[20] ISO 9705 (1993). Fire Tests: Full-Scale Room Test for Surface Products. (1 ${ }^{\text {st }}$ ed.). International Organization for Standardization: Geneva, Switzerland.

[21]Hurley, M. J. (2016). SFPE Handbook of Fire Protection Engineering. (5 ${ }^{\text {th }}$ ed.). SFPE, Quincy, Massachusetts.

[22] Vipin, V. (2012). Image processing based forest detection. International Journal of Emerging Technology and Advanced Engineering, 2, 87-95.

[23] Celik, T., Demirel, H., Ozkaramanli, H., \& Uyguroglu, M. (2007). Fire detection using statistical color model in video sequences. Journal of Visual Communication and Image Representation, 18, 176-185.

[24] Audoin, L., Kolb, G., Torero, J. L., \& Most, J. M. (1995). Average centreline temperatures of a buoyant pool fire obtained by image processing of video recordings. Fire Safety Journal, 24, 167-187.

[25] Thomas, P. H., \& Law, M. (1972). The Projection of Flames from Burning Buildings. Fire Research Station, Fire Research Note, No 921, Borehamwood, USA.

[26] Hu, L., Lu, K., Delichatsios, M., He, L., \& Tang, F. (2012). An experimental investigation and statistical characterization of intermittent flame ejecting behaviour of enclosure fires with an opening. Combustion and Flame, 159, 1178-1184.

[27] Gottuk, D. T., Roby, R. J., \& Beyler, C. L. (1992). A study of CO and smoke yields from compartment fires with external burning. Proceedings of the Combustion Institute, 24, 17291735 .

[28]Lee, Y., Delichatsios, M. A., \& Silcock, G. W. H. (2008). Heat flux distribution and flame shapes on the inert façade. Fire Safety Science, 9, 193-204. 
Nomenclature

\begin{tabular}{|c|c|c|}
\hline Symbol & Units & Description \\
\hline$A_{T}$ & $\left(\mathrm{~m}^{2}\right)$ & Total area of enclosure (walls, ceiling and floor, including openings) \\
\hline$A_{v}$ & $\left(\mathrm{~m}^{2}\right)$ & Total area of the opening(s) \\
\hline$C_{p}$ & $(1005 \mathrm{~J} / \mathrm{kgK})$ & Specific heat of air at ambient conditions \\
\hline$D_{v}$ & $\left(\mathrm{~m}^{2}\right)$ & "Effective" area of the fire source \\
\hline$g$ & $\left(9.81 \mathrm{~m} / \mathrm{s}^{2}\right)$ & Gravitational acceleration \\
\hline$h_{e q}$ & $(\mathrm{~m})$ & Average height of the opening(s) \\
\hline$H_{u}$ & $(\mathrm{~kJ} / \mathrm{kg})$ & Lower heating value of $n$-hexane \\
\hline$l$ & $(-)$ & Characteristic length scale \\
\hline$L_{f-0.05}$ & $(\mathrm{~m})$ & Flame height at the "continuous flame" ( $5 \%$ flame intermittency limit) \\
\hline$L_{f \_} 0.50$ & $(\mathrm{~m})$ & Flame height at the "intermittent flame" (50\% flame intermittency limit) \\
\hline$L_{f \_} 0.95$ & $(\mathrm{~m})$ & Flame height at the "far-field flame" (95\% flame intermittency limit) \\
\hline$L_{f, m}$ & $(\mathrm{~m})$ & Mean EVF height \\
\hline$L_{H}$ & $(\mathrm{~m})$ & EVF projection \\
\hline$L_{L}$ & $(\mathrm{~m})$ & EVF height \\
\hline$\dot{m}_{a}$ & $(\mathrm{~kg} / \mathrm{s})$ & Mass flow rate of ambient air entering the fire compartment \\
\hline$m_{f}$ & $(\mathrm{~kg})$ & Fuel mass \\
\hline$\dot{m}_{f}$ & $(\mathrm{~kg} / \mathrm{s})$ & Fuel mass loss rate \\
\hline$P$ & $(-)$ & EVF probability \\
\hline$q_{f}$ & $\left(\mathrm{MJ} / \mathrm{m}^{2}\right)$ & Fire load density \\
\hline$\dot{Q}_{t o t}$ & $(\mathrm{~kW})$ & Heat release rate \\
\hline$\dot{Q}_{e x}$ & $(\mathrm{~kW})$ & Excess heat release rate \\
\hline$\dot{Q}_{i n, \max }$ & $(\mathrm{kW})$ & Heat release rate at the interior of the compartment \\
\hline$R H_{\infty}$ & $(\%)$ & Ambient air relative humidity \\
\hline$T_{\infty}$ & $\left({ }^{\circ} \mathrm{C}\right)$ & Ambient air temperature \\
\hline$t_{d u r}$ & $(\mathrm{~s})$ & Total fire duration \\
\hline$V_{f}$ & (lt) & Fuel volume \\
\hline$w_{d}$ & $(\mathrm{~m})$ & Distance to any other window \\
\hline$w_{f}$ & $(\mathrm{~m})$ & EVF width \\
\hline$w_{t}$ & $(\mathrm{~m})$ & Sum of opening widths on all walls of the burning room \\
\hline$Z_{n}$ & $(\mathrm{~m})$ & Neutral plane height \\
\hline$\rho_{\infty}$ & $\left(\mathrm{kg} / \mathrm{m}^{3}\right)$ & Ambient air density \\
\hline \multicolumn{3}{|c|}{ Abbreviations } \\
\hline $\mathrm{CB}$ & \multicolumn{2}{|c|}{ Compartment Back } \\
\hline $\mathrm{CF}$ & \multicolumn{2}{|c|}{ Compartment Front } \\
\hline CFD & \multicolumn{2}{|c|}{ Computational Fluid Dynamics } \\
\hline EVF & \multicolumn{2}{|c|}{ Externally Venting Flames } \\
\hline GER & \multicolumn{2}{|c|}{ Global Equivalence Ratio } \\
\hline OV & \multicolumn{2}{|c|}{ Over-ventilated conditions } \\
\hline UV & \multicolumn{2}{|c|}{ Under-ventilated conditions } \\
\hline
\end{tabular}




\section{Figure Captions}

Figure 1. General schematic illustrating the main characteristics of EVF.

Figure 2. Schematic drawing of the experimental facility and sensor locations; side (left) and top (right) section.

Figure 3. Measurements of instantaneous fuel mass consumption rate.

Figure 4. Temporal variation of upper gas layer temperature at the interior of the fire compartment;

Figure 5. Vertical distribution of time-averaged air temperature at the interior of the fire compartment.

Figure 6. Vertical distribution of time-averaged mean EVF temperatures, at a distance of 123 $\mathrm{mm}$ (T1C) and $246 \mathrm{~mm}$ (T2C) from the façade.

Figure 7. Temporal variation of EVF gas temperature for different height levels $(850 \mathrm{~mm}$ and $1500 \mathrm{~mm})$, distances from the facade $(123 \mathrm{~mm}$ and $246 \mathrm{~mm})$ and façade width locations (centreline and $1 / 4$ width).

Figure 8. Time-averaged flame intermittency for test cases D-1.00L (left), D-2.35L (middle) and D-4.70L (right); front (top) and side (bottom) view.

Figure 9. Determination of the mean flame height using experimental data and empirical correlations.

Figure 10. Temporal evolution of instantaneous flame height estimations for test case D-4.70L.

Figure 11. Determination of the mean flame projection, at a height of $0.9 \mathrm{~m}$, using experimental data and empirical correlations.

Figure 12. Vertical distribution of the time-averaged EVF width (left) and projection (right). 
Table 5. Summary of EVF dimensions relative error estimation using semi-empirical correlations.

\begin{tabular}{|c|c|c|c|c|c|c|c|}
\hline \multirow{3}{*}{ Correlations } & \multicolumn{7}{|c|}{ Test cases } \\
\hline & \multicolumn{3}{|c|}{ Medium scale } & \multicolumn{4}{|c|}{ Large scale } \\
\hline & D-1.00L & D-2.35L & D-4.70L & 2 & 8 & 28 & 29 \\
\hline H1 & OR & OR & $+55.1 \%$ & $+6.0 \%$ & $-37.4 \%$ & $-130.7 \%$ & $-37.3 \%$ \\
\hline $\mathrm{H} 2$ & OR & $+12.7 \%$ & $+25.6 \%$ & $-15.2 \%$ & $+1.1 \%$ & $+21.3 \%$ & $-0.1 \%$ \\
\hline H3 & OR & $+8.7 \%$ & $+43.3 \%$ & $-38.4 \%$ & $-18.0 \%$ & $+2.9 \%$ & $-25.5 \%$ \\
\hline $\mathrm{P} 1$ & $+114.0 \%$ & $+40.8 \%$ & $+31.6 \%$ & NA & $+50.0 \%$ & $+23.8 \%$ & NA \\
\hline $\mathrm{P} 2$ & $-30.1 \%$ & $-71.3 \%$ & $-25.4 \%$ & NA & $-30.6 \%$ & $-362.9 \%$ & NA \\
\hline $\mathrm{P} 3$ & $+4.8 \%$ & $-56.9 \%$ & $+10.4 \%$ & NA & $+53.7 \%$ & $-215.7 \%$ & NA \\
\hline $\mathrm{P} 4$ & $-34.5 \%$ & $-74.1 \%$ & $-31.3 \%$ & NA & $-24.2 \%$ & $-362.9 \%$ & NA \\
\hline$w_{f}$ & OR & OR & $-105.0 \%$ & NA & NA & NA & NA \\
\hline
\end{tabular}

OR: Out of range, NA: Not available 